\title{
Association between device-measured physical activity and lumbar Modic changes
}

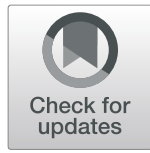

Marella Modarress Julin ${ }^{1,2,3^{*}}$, Jesperi Saukkonen ${ }^{1,2}$, Petteri Oura ${ }^{1,2,4}$, Maisa Niemelä1,4, Juho-Antti Junno ${ }^{2,5,6}$, Juhani Määttä ${ }^{1,2}$, Jaakko Niinimäki ${ }^{1,4}$, Timo Jämsä ${ }^{1,4,7}$, Raija Korpelainen ${ }^{1,2,8}$ and Jaro Karppinen ${ }^{1,2,9}$

\begin{abstract}
Background: Modic changes (MC) in the lumbar spine are considered one potential etiological factor behind low back pain (LBP). Multiple risk factors for MC have been suggested, including male gender, smoking and factors affecting hyperloading and mechanical stress such as high body mass index (BMI), strenuous physical work and high occupational and leisure-time physical activity (PA). So far, the effect of PA on the occurrence of MC has remained under debate due to contradictory findings. The purpose of this study was to investigate the possible association between device-measured moderate-to-vigorous PA (MVPA) ( $\geq 3.5$ METs) and lumbar MC.

Methods: The study had 1374 participants from the Northern Finland Birth Cohort 1966. At the age of 46-48, PA was measured by a wrist-worn accelerometer, and lumbar magnetic resonance imaging (MRI) was carried out to determine MC. We analyzed the association between Type 1 (MC1) and Type 2 (MC2) MC and daily amount of MVPA (min/day) using sex-stratified logistic regression models before and after adjustment for BMI, socioeconomic status, smoking, and accelerometer wear time.
\end{abstract}

Results: Among men, increased amount of MVPA was positively associated with any MC (adjusted OR corresponding to every $60 \mathrm{~min} /$ day of MVPA 1.41; 95\% confidence interval (Cl) 1.01 to 1.95) and MC2 (OR 1.54; 95\% $\mathrm{Cl} 1.14$ to 2.08 ), but not with MC1 (OR 1.06; $95 \% \mathrm{Cl} 0.80$ to 1.39). Among women, we only found a positive association between MVPA and MC1 before adjustments (unadjusted OR 1.42; $95 \% \mathrm{Cl} 1.06$ to 1.92).

Conclusion: Among men, increased amount of MVPA was associated with increased odds of any MC and particularly MC2. Among women, MVPA was not independently associated with MC.

Keywords: Physical activity, MVPA, Device-based measurements, Modic changes, Lumbar spine, Lumbar MRI, Cohort study, Vertebrae, Skeletal health

\section{Background}

It has been suggested that Modic changes $(\mathrm{MC})$ in the lumbar spine are associated with non-specific low back pain (LBP) [1-4], although a recent systematic review showed this association to be inconsistent [5]. MC are lesions of vertebral bone marrow adjacent to vertebral endplates seen in magnetic resonance imaging (MRI)

\footnotetext{
* Correspondence: marella.julin@oulu.fi

${ }^{1}$ Medical Research Center Oulu, Oulu University Hospital and University of Oulu, PO Box 5000, Fl-90014 Oulu, Finland

${ }^{2}$ Center for Life Course Health Research, PO Box 5000, Fl-90014 Oulu, Finland Full list of author information is available at the end of the article
}

and are further divided into Type 1 (MC1), Type 2 (MC2) and Type 3 (MC3) on the basis of their different appearances in T1- and T2-weighted images [1, 6-8]. It is believed that the same pathologic processes lead to different types of MC. Histological studies show that $\mathrm{MC} 1$ is the acute phase, signifying an inflammatory reaction of the bone marrow, whereas MC2 represent fat infiltration and MC3 a sclerotic change of the bone marrow [5-8].

Despite decades of research on MC, their etiology remains unknown [9]. Both mechanical stress and bacterial 
infection are proposed to play a key role in the development of MC $[1,5,9]$. Age and damage of the endplates and intervertebral discs, such as disc degeneration (DD) and endplate defect, have been consistently associated with MC [9-13]. Multiple other risk factors for MC have also been suggested, including male gender, smoking and factors affecting hyperloading and mechanical stress such as high body mass index (BMI), strenuous physical work and high occupational and leisure-time physical activity (PA) $[1,11,14,15]$.

As regards the association between $\mathrm{PA}$ and $\mathrm{MC}$, knowledge is limited and findings are controversial; some results have indicated no association between intense PA and MC $[11,16,17]$ whereas others have proposed an association [15]. Somewhat indistinct results have also been reported [14]. The hypothesis behind the association between PA and MC is that a high level of intense PA could cause excessive loading in the motion segment of the spine, i.e. intervertebral disc and adjacent endplates and vertebrae, eventually leading to damage of the disc and endplate followed by chronic inflammation and possibly MC-related edema $[9,18,19]$.

As the pathophysiology and etiology of $\mathrm{MC}$ and the association between MC and LBP are still under eager debate, the clinical significance of $\mathrm{MC}$ also remains controversial $[2,5,20]$. Meanwhile, evidence of a higher prevalence of MC among LBP patients than among the general population [21] warrants a more comprehensive understanding of MC. Thus, investigating the possible risk factors is crucial to obtain a more profound comprehension of the etiology and clinical importance of MC. The objective of this study was to determine whether device-measured moderate-to-vigorous PA (MVPA) is associated with lumbar MC. The hypothesis was that higher amount of MVPA would be associated with lumbar MC.

\section{Methods}

\section{Study design}

The aim of this cross-sectional study was to investigate the possible association between device-measured MVPA and lumbar MC. We used accelerometers to measure $\mathrm{PA}$, and the presence of $\mathrm{MC}$ was determined from lumbar MRI scans of the Northern Finland Birth Cohort 1966 (NFBC1966) members, the final study population being 1374 individuals. Presentation of the study setting conform to the guidelines for reporting observational studies (STROBE) [22].

\section{Selection of study participants from birth cohort population}

The collection of Northern Finland Birth Cohort 1966 (NFBC1966) data started in 1965. Pregnant women living in Oulu and Lapland were asked during their maternity clinic appointment to take part in the NFBC1966. The inclusion criterion was that the child's expected date of birth was between January 1st and December 31st, 1966. Since then, the mothers $(n=12,068)$ and children $(n=12,231)$ have been followed through regular postal questionnaires, clinical examinations and data collected from health care records [23, 24].

The members of the NFBC1966 whose contact information was available and up to date $(n=10,321)$ received postal questionnaires in 2012-2014, and 6825 (66\%) individuals aged 46 to 48 at that time responded. In addition, those who lived in Finland were asked to take part in clinical examinations, and 5861 (57\%) individuals did so. A trained study nurse measured the height and weight of the participants, and based on these measurement values, BMI $(\mathrm{kg} / \mathrm{m} 2)$ was calculated. The participants were asked about smoking as follows: 1) "Have you ever smoked cigarettes (yes/no)?" and 2) "Do you currently smoke (yes/no)?" Based on the answers, three groups were created: 1) non-smokers, 2) former smokers and 3) current smokers. Socioeconomic status was defined as attended school years ( $\leq 9$ years, 9-12 years, $>12$ years) and we specified basic education using response options of: 1) Less than 9 years of elementary school, 2) comprehensive school, or 3) matriculation examination. Furthermore, participants $(n=1988)$ who lived up to $100 \mathrm{~km}$ from the city of Oulu received an invitation to undergo lumbar MRI at the Oulu University Hospital. A total of 1540 underwent MRI, but after excluding participants with missing images, imaging modalities, covariates, or PA data, the final sample size was 1374 individuals.

\section{Physical activity assessment}

The PA assessment was part of the NFBC1966 premeditated follow-up organized in 2012-2014. The participants wore a waterproof accelerometer, Polar Active (Polar Electro, Kempele, Finland), which has a 21-day memory, for at least 14 days and $24 \mathrm{~h}$ per day, on their non-dominant wrist $[25,26]$. Polar Active uses age, sex, height and weight as predefined inputs, and metabolic equivalent (MET) values with an epoch length of $30 \mathrm{~s}$ are received [26]. Energy expenditure (EE) during exercise training has been determined, and good correlation $\left(R^{2}=0.74\right)$ between the Polar Active and the doubly labeled water technique has been found previously $[25,27]$. Participants with at least four valid days were included in the analysis [28]. If at least $600 \mathrm{~min} /$ day, i.e. $10 \mathrm{~h}$ per day monitoring time during waking hours were recorded, this was included as a valid analysis day. However, the day on which the participants received the accelerometer was excluded. Daily duration averages (min/day) were defined at five activity levels (very light: 1-2 
MET, light: 2-3.5 MET, moderate: 3.5-5 MET, vigorous: 5-8 MET and very vigorous: $\geq 8$ MET) using the threshold values presented by the manufacturer [26]. We assessed MVPA as all activity at an intensity of at least 3.5 METs (min/day), and converted the values to $60 \mathrm{~min} /$ day, i.e. $1 \mathrm{~h}$ per day, for the analyses. The MVPA (min/day) range was 5-272 (i.e. $0.08-4.53 \mathrm{~h} /$ day) for men and 7-245 (i.e. $0.11-4.09 \mathrm{~h} /$ day) for women, whereas wear time ( $\mathrm{min} /$ day) range was $722-1171 \quad(12.04-19.52 \mathrm{~h} /$ day $)$ and $718-1132$ (11.97-18.86 h/day) for men and women, respectively. The number of valid days ranged from 4 to 17 for men and 4 to 16 for women.

\section{Determination of MC from lumbar MRI}

Lumbar MR images of the included participants were obtained by the staff of the department of radiology, Oulu University Hospital, using 1.5-T MRI (Signa HDxt, General Electric, Milwaukee, WI) in 2012-2014 (participants aged 46-48). The imaging was performed by T2weighted fast-recovery fast spin-echo (frFSE) images in the sagittal (repetition time/effective echo time (TR/ effTE) $3500 / 112 \mathrm{~ms}, 4$ averages, field-of-view (FOV) $280 \times 280 \mathrm{~mm}$, acquisition matrix $448 \times 224$, slice thickness $3 \mathrm{~mm}$ with $1 \mathrm{~mm}$ interslice gap) and transverse planes (TR/effTE 3600/118 ms, 4 averages, FOV $180 \times$ $180 \mathrm{~mm}$, acquisition matrix $256 \times 224$, slice thickness 4 $\mathrm{mm}$ with $1 \mathrm{~mm}$ interslice gap) and T1-weighed fluidattenuated inversion recovery sequence images in the sagittal plane (TR/effTE $860 / 20 \mathrm{~ms}$, inversion time (TI) of $1969 \mathrm{~ms}, 1.5$ averages, FOV $280 \times 280 \mathrm{~mm}$, acquisition matrix $256 \times 224$, slice thickness $3 \mathrm{~mm}$, interslice gap 4 $\mathrm{mm})$. The scans were accessed using NeaView Radiology software (Neagen Oy, Oulu, Finland), version 2.31.

The evaluation of $\mathrm{MC}$ has been previously described elsewhere [4]. The same researcher (JS) analyzed the presence and classification of different types of MC in all the scans using the classification method previously described by Määttä et al. [12]. The intra- and interobserver reliability, determined by Cohen's Kappa/ weighted Kappa, was good for the general presence of $\mathrm{MC}$ and the type of MC (for more information, see Saukkonen et al. [4]).

\section{Ethics}

The study protocol followed the Declaration of Helsinki and we obtained the consent of the Ethical Committee of the Northern Ostrobothnia Hospital District. The cohort members participated voluntarily and anonymously; informed consent was signed at each level of the study and recognition of individuals was made impossible by using identification codes instead of personal details.

\section{Statistical analyses}

SPSS version 24 (IBM, Armonk, New York, USA) was used for analyzing the data. The threshold for statistical significance was $P=0.05$. Descriptive statistics were calculated as means with standard deviations (SD) or medians with interquartile ranges (IQR) for continuous variables, depending on the normality of the data, and as percentages and frequencies for categorical variables. Logistic regression models were used when determining the association between MVPA and lumbar MC. Any $\mathrm{MC}, \mathrm{MC} 1$ and $\mathrm{MC} 2$ were used as separate outcomes, for which we ran crude and adjusted regression models. MVPA (60 min/day, continuous) served as the primary explanatory variable. The following covariates were also included in the adjusted models: body mass index (continuous), socioeconomic status (categorical), smoking (categorical), and accelerometer wear time (continuous). As significant sex interactions were present $(P$ values for the sex"MVPA interaction terms in pooled-sex models $\leq 0.022$ ), all the models were stratified by sex. Odds ratios (OR), their 95\% confidence intervals (CI), and the respective $P$ values were collected from the data output. Analysis of representativeness was also performed, comparing individuals included in the sample to the rest of the NFBC1966 population. We used the chi-square test for categorial variables, the independent $\mathrm{T}$-test for continuous variables with normal distributions, and the Mann-Whitney U-test for continuous variables with skewed distributions.

\section{Results}

The characteristics of the study population, which comprised 640 men and 734 women, are presented in Table 1. The median amount of MVPA was $73 \mathrm{~min} /$ day among men and $57 \mathrm{~min} /$ day among women. The prevalence of any MC was 74\% among men and $60 \%$ among women. As regards the type of MC, $33 \%$ of both sexes had MC1, whereas MC2 was observed among 65 and $44 \%$ of men and women, respectively. Among men, daily amount of MVPA was positively associated with any MC and $\mathrm{MC}$, and these associations persisted after full adjustments (Table 2). Among women, we only observed a positive association between MVPA and MC1 before adjustments (Table 3 ).

\section{Discussion}

According to our present results, increased amount of MVPA was associated with increased odds of any MC (adjusted OR corresponding to every $60 \mathrm{~min} /$ day of MVPA 1.41; 95\% confidence interval (CI) 1.01 to 1.95 ) and especially MC2 (OR 1.54; 95\% CI 1.14 to 2.08) among men, whereas among women, MVPA was not independently associated with $\mathrm{MC}$. In other words, among men, the odds of any MC increase by $41 \%$ and of $\mathrm{MC} 2$ 
Table 1 Characteristics of study participants $(n=1374)$ and those excluded from sample ( $n$ varies due to missing data)

\begin{tabular}{|c|c|c|c|c|c|c|}
\hline & \multicolumn{2}{|l|}{ Sample } & \multicolumn{2}{|l|}{ Excluded } & \multicolumn{2}{|c|}{$\begin{array}{l}\text { P for difference } \\
\text { between Sample } \\
\text { and Excluded }\end{array}$} \\
\hline & $\begin{array}{l}\text { Men } \\
(n=640)\end{array}$ & $\begin{array}{l}\text { Women } \\
(n=734)\end{array}$ & Men & Women & Men & Women \\
\hline Age, years; mean $\left(S D^{a}\right)$ & $46.8(0.4)$ & $46.8(0.4)$ & $46.8(0.5)$ & $46.8(0.4)$ & 0.723 & 0.426 \\
\hline $\mathrm{BMI}^{\mathrm{b}}, \mathrm{kg} / \mathrm{m}^{2} ;$ mean (SD) & $27.0(3.7)$ & $26.2(5.0)$ & $27.4(4.4)$ & $26.6(5.4)$ & 0.021 & 0.075 \\
\hline Education years; \% (n) & & & & & 0.143 & 0.003 \\
\hline$\leq 9$ & $3.3(21)$ & $2.9(21)$ & $4.7(142)$ & $3.5(127)$ & & \\
\hline $9-12$ & $73(467)$ & $71.3(523)$ & $72.9(2222)$ & $65.9(2405)$ & & \\
\hline$>12$ & $23.8(152)$ & $25.9(190)$ & $22.5(685)$ & $30.6(1117)$ & & \\
\hline Smoking; \% (n) & & & & & $<0.001$ & 0.018 \\
\hline Non-smoker & $48.8(312)$ & $59.8(439)$ & $44.7(1349)$ & $57.2(2064)$ & & \\
\hline Former smoker & $34.4(220)$ & $24.7(181)$ & $30.4(917)$ & $23.6(853)$ & & \\
\hline Current smoker & $16.9(108)$ & $15.5(114)$ & $24.9(750)$ & $19.2(693)$ & & \\
\hline \multicolumn{7}{|l|}{ Accelerometer data } \\
\hline Moderate to vigorous $\mathrm{PA}^{\mathrm{c}}$, min/day; median $\left(\mathrm{IQR}^{\mathrm{d}}\right)$ & $73(53-97)$ & $57(40-76)$ & $73(52-97)$ & $56(41-76)$ & 0.881 & 0.845 \\
\hline Wear time, min/day; median (IQR) & $990(948-1026)$ & $972(936-1008)$ & $990(948-1032)$ & $978(942-1008)$ & 0.101 & 0.079 \\
\hline \multicolumn{7}{|l|}{ Prevalence of $\mathbf{M C}^{\mathrm{e}} ; \%(\mathrm{n})$} \\
\hline Any MC & $74.4(476)$ & $59.7(438)$ & $75.2(528)$ & $60.1(478)$ & 0.098 & 0.455 \\
\hline MC1 & $32.7(209)$ & $31.7(233)$ & $32.4(230)$ & $31.0(248)$ & 0.708 & 0.113 \\
\hline MC2 & $65.3(418)$ & $44.4(326)$ & $65.7(466)$ & $44.3(355)$ & 0.479 & 0.858 \\
\hline
\end{tabular}

${ }^{\mathrm{a}}$ Standard deviations, ${ }^{\mathrm{b}}$ Body mass index, ${ }^{\mathrm{C}}$ Physical activity, ${ }^{\mathrm{d}}$ Interquartile range, ${ }^{\mathrm{e}}$ Modic changes

by $54 \%$ if MVPA increased by $1 \mathrm{~h} /$ day. These findings strengthen the understanding of an association between $\mathrm{PA}$ and MC, especially MC2.

It is widely accepted that the same pathologic processes may lead to different types of MC, also suggesting that the more acute phase, i.e. Type 1 , is interconvertible with Type 2, and that Type 3 is the late sclerotic phase [7-9]. Evidence from mixed types supports the interconvertibility of all types of MC $[9,14]$. Various etiological factors leading to $\mathrm{MC}$ are debated. It has been suggested that $\mathrm{MC1}$ results from bacterial infection and occult discitis, or an autoimmune reaction $[1,9,29,30]$, whereas $\mathrm{MC} 2$ is more strongly related to hyperloading and degenerative changes of the motion segment $[9,14,31$, 32]. Our current results are in line with these hypotheses, as we found no significant association between MVPA and MC1 among either sex in the adjusted models, but among men, increased amount of MVPA was positively associated with $\mathrm{MC} 2$, strengthening the hypothesis regarding a connection between hyperloading and MC2 [9, 14, 31, 32].

Biomechanical theory proposes that changed mechanical conditions in and around the intervertebral disc lead to microfractures of the vertebral endplate, which in turn, can lead to inflammatory processes seen as edema $[1,9,20]$. If mechanical stress and increased loading of the motion segment are considered potential contributors to the development of $\mathrm{MC}[1,9,20]$, intense PA could be hypothesized as a potential risk factor [33]. The findings concerning an association between PA and MC have been inconsistent [11, 1416]. Kuisma et al. [14] studied the determinants of $\mathrm{MC}$ and found a significant association between questionnaire-based leisure-time $\mathrm{PA}$ and $\mathrm{MC}$ for all MC but not for MC1 or MC2 separately. Nevertheless, the authors speculated that mechanical loading

Table 2 Association between moderate to vigorous physical activity (MVPA) and Modic changes (MC) among men ( $n=640)$ according to multivariable logistic regression models. Odds ratios (OR) correspond to every 60 min/day, i.e. 1 h per day, of MVPA

\begin{tabular}{|c|c|c|c|c|c|c|c|c|c|}
\hline & \multicolumn{3}{|c|}{ Any MC } & \multicolumn{3}{|l|}{ MC1 } & \multicolumn{3}{|c|}{ MC2 } \\
\hline & OR & $95 \% \mathrm{Cl}^{\mathrm{b}}$ & $P$ & OR & $95 \% \mathrm{Cl}$ & $P$ & OR & $95 \% \mathrm{Cl}$ & $P$ \\
\hline Unadjusted & 1.31 & $0.97,1.78$ & 0.080 & 1.06 & $0.81,1.38$ & 0.679 & 1.40 & $1.06,1.85$ & 0.018 \\
\hline Adjusted $^{a}$ & 1.41 & $1.01,1.95$ & 0.042 & 1.06 & $0.80,1.39$ & 0.686 & 1.54 & $1.14,2.08$ & 0.005 \\
\hline
\end{tabular}

${ }^{a}$ Adjusted for BMI (body mass index, $\mathrm{kg} / \mathrm{m} 2$ ), smoking, education years and accelerometer wear time

${ }^{b}$ Confidence interval 
Table 3 Association between moderate to vigorous physical activity (MVPA) and Modic changes (MC) among women ( $n=734$ ) according to multivariable logistic regression models. Odds ratios (OR) correspond to every 60 min/day, i.e. 1 h per day, of MVPA

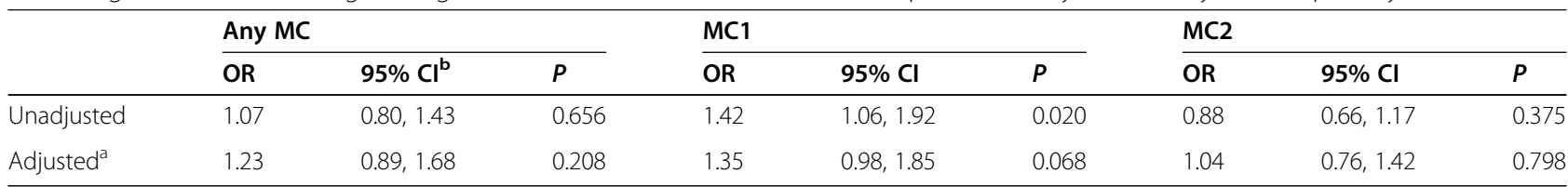

${ }^{a}$ Adjusted for BMI (body mass index, $\mathrm{kg} / \mathrm{m} 2$ ), smoking, education years and accelerometer wear time

${ }^{b}$ Confidence interval

due to high PA may damage endplates, thereby activating catabolic processes and resulting in MC.

In a Danish study, hard occupational PA, evaluated through questionnaires, was associated with MC among 40-year-olds, and the association was stronger among overweight participants and heavy smokers [15]. A more recent study [18] found a four times greater incidence of $\mathrm{MC}$ among study participants who did strenuous physical work than among participants who did light physical work. The authors speculated that the compression stresses and forces directed toward endplates during long-term strenuous physical work exceed the loadbearing capacity of endplates and result in damage that can gradually lead to the development of MC [18]. Our results are in line with the above-mentioned findings, as an increased amount of at least moderate intensity PA was associated with an increased likelihood of any $\mathrm{MC}$ and particularly MC2, although among women MVPA was not independently associated with MC.

Controversially, opposite findings have also been made $[11,16,17,34]$. Jensen et al. [11] investigated the predictors of MC, i.e. high work and/or leisure-time PA, and concluded that PA did not predict MC. Arana et al. [16] similarly found no association between occupational or leisure-time PA and $\mathrm{MC}$, but did find an association between DD and MC. More recent studies by Mok et al. [34] and Wu et al. [17] also investigated the relationship between $\mathrm{MC}$ and occupational and leisure-time PA, making the same conclusion of no association between PA and MC.

We found a significant association between increased amount of MVPA and MC among men but not among women. We do not know the reason for the sex difference, but speculate that men may be exposed to more hyperloading of the spine. The reason for the observed differences between the sexes has also remained indistinct in previous research. Leboeuf-Yde et al. [15] found no significant differences when analyzing the associations separately for men and women. Jensen et al. [11] found that gender did not predict MC, whereas Arana et al. [16] stated that male sex was associated with MC, and Han et al. [18] and Wu et al. [17] discovered an association between female sex and MC.

The strength of the present study is its large sample that included over 1300 individuals of the Northern Finnish population, thus increasing the relevance of the results when considering the applicability at the population level [35]. The representativeness analyses showed that the selected study participants were a representative sample of the total cohort population. Only small statistically significant but clinically non-relevant differences were found in BMI among men, smoking among both sexes and education years among women (Table 1). Thus, the groups were similar, and representativeness was good, as also demonstrated in our previous study [35].

The measurement of PA using an accelerometer can also be regarded as a strength of the study. In most previous studies investigating the association between PA and MC, PA assessment has relied on subjective selfreporting [11, 14-18, 34]. Currently, device-based measurement of PA is frequently preferred over subjective self-reporting of PA through, for example, questionnaires, as self-reporting of PA is prone to over- or underestimation of actual PA as well as recall and response bias. Meanwhile, accelerometers are considered proportionately sensitive and reliable, thus feasible for measuring PA [36-38].

Nevertheless, device-based monitoring of PA has its own limitations. Accelerometers cannot detect all varieties of motion, such as static activities (e.g. resistance training or cycling), and this may potentially lead to a biased estimation of total energy expenditure. Thus, the use of accelerometers can be also seen as a limitation [39-41]. However, the current trend is device-based measurement of PA and it is considered a more accurate measurement method than self-reporting of PA [39, 42]. We selected a wrist-worn over a waist-worn monitor as its wearing compliance has been found to be higher, and it has also been chosen by the National Health and $\mathrm{Nu}$ trition Examination Survey (NHANES) [43]. In the present study, the accelerometer was validated using the doubly labeled water technique. Good correlation for measuring energy expenditure during PA was detected $(R=0.86)$.

The cross-sectional study design can be considered the main limitation of this study as it prevents making conclusions about the causal relationship. The intensity of PA used in the assessments can also be seen as a limitation, as the association between MC and MVPA cannot be generalized to all PA. On the other hand, the possible 
beneficial role of light PA in bone health cannot be disregarded. There is broad discussion on the health effects of light PA of different intensities [44] as well as vibration exercises in terms of the prevention of falls and fractures [45]. Variety in PA can also be regarded as a limitation, as it makes it difficult to estimate the association of a specific activity with MC. Thus, we cannot contradict that lighter PA or specific activity could have even beneficial effects on lumbar MC. It can also be speculated whether a two-week period is truly representative of a person's average activity level. However, earlier studies have indicated that monitoring of three to 7 days provides reliable estimates of PA behavior [42, 4649]. Furthermore, an individual's level of PA is assumed to be quite a stabile trait, meaning that the individuals who were physically active at the time of the study will presumably stay active during other periods of life [50]. Thus, it can be assumed that measuring PA over 2 weeks provides a reliable insight into the participants' usual PA behavior.

\section{Conclusions}

Among men, increased amount of PA reaching at least moderate intensity was associated with increased odds of any $\mathrm{MC}$ and particularly MC2; the odds of any MC increased by $41 \%$ and for MC2 by $54 \%$ if their MVPA increased by $1 \mathrm{~h} /$ day. Among women, MVPA was not associated with MC. It seems that PA may have clinical relevance among men in the form of increased likelihood of MC. Nevertheless, as the association between MC and LBP is still unclear, the clinical significance of the present results also remains debatable and further studies should be carried out to determine whether there is a meaningful and significant connection between PA and MC.

\section{Abbreviations \\ MC: Modic changes; LBP: Low back pain; PA: Physical activity; MVPA: Moderate-to-vigorous physical activity; MET: Metabolic equivalent; NFBC1966: Northern Finland Birth Cohort 1966; MRI: Magnetic resonance imaging; MC1: Type 1 Modic changes; MC2: Type 2 Modic changes; MC3: Type 3 Modic changes; BMI: Body mass index; OR: Odds ratio; 95\% Cl: 95\% confidence interval; DD: Disc degeneration; EE: Energy expenditure; frFSE : Fast-recovery fast spin-echo; TR/effTE: Repetition time/effective echo time; FOV: Field-of-view; SD: Standard deviation; IQR: Interquartile range}

\section{Acknowledgements}

We thank the late Professor Paula Rantakallio (launch of NFBC1966), the participants in the 46y study and the NFBC project center.

\section{Authors' contributions}

MM, PO, JJ, TJ, RK and JK designed the study. JN was in charge of lumbar MR imaging. JS analyzed the presence and classification of different types of $M C$ in all the scans. JM evaluated the 700 images that were used in the interrater analysis. MM, PO, JS and MN drafted the manuscript and performed the statistical analysis. All the authors read, revised and approved the final manuscript.

\section{Funding}

The NFBC1966 received financial support from University of Oulu Grant no. 24000692, Oulu University Hospital Grant no. 24301140, and ERDF European Regional Development Fund Grant no. 539/2010 A31592. The study was financially supported by the Ministry of Education and Culture of Finland, grant numbers OKM/86/626/2014, OKM/43/626/2015 and OKM/17/626/2016, and Infotech Oulu, Finland.

\section{Availability of data and materials}

The datasets used and analyzed during the current study are not publicly available due to local privacy regulations but are available from the corresponding author on reasonable request.

\section{Ethics approval and consent to participate}

The study was conducted in accordance with the Declaration of Helsinki and approved by the Ethical Committee of the Northern Ostrobothnia Hospital District. The cohort members participated voluntarily and anonymously, and informed consent was signed at each stage of the study.

\section{Consent for publication}

Not applicable.

\section{Competing interests}

The authors declare that they have no competing interests except for the funding disclosed above.

\section{Author details}

${ }^{1}$ Medical Research Center Oulu, Oulu University Hospital and University of Oulu, PO Box 5000, FI-90014 Oulu, Finland. ${ }^{2}$ Center for Life Course Health Research, PO Box 5000, Fl-90014 Oulu, Finland. ${ }^{3}$ Clinic of Physiatry, Oulu University Hospital (OYS), PO Box 21, 90029 Oulu, Finland. ${ }^{4}$ Research Unit of Medical Imaging, Physics and Technology, Faculty of Medicine, University of Oulu, PO Box 5000, FI-90014 Oulu, Finland. ${ }^{5}$ Cancer and Translational Medicine Research Unit, Faculty of Medicine, University of Oulu, PO Box 5000, Fl-90014 Oulu, Finland. ${ }^{6}$ Department of Archaeology, Faculty of Humanities, University of Oulu, PO Box 5000, Fl-90014 Oulu, Finland. ${ }^{7}$ Diagnostic Radiology, Oulu University Hospital (OYS), P.O. Box 10, Fl-90029 Oulu, Finland. ${ }^{8}$ Department of Sports and Exercise Medicine, Oulu Deaconess Institute Foundation, PO Box 365, FI-90100 Oulu, Finland. ${ }^{9}$ Finnish Institute of Occupational Health, Aapistie 1, Fl-90220 Oulu, Finland.

Received: 3 April 2020 Accepted: 8 September 2020 Published online: 25 September 2020

\section{References}

1. Albert HB, Kjaer P, Jensen TS, Sorensen JS, Bendix T, Manniche C. Modic changes, possible causes and relation to low back pain. Med Hypotheses. 2008:70:361-8.

2. Kjaer P, Korsholm L, Bendix T, Sorensen JS, Leboeuf-Yde C. Modic changes and their associations with clinical findings. Eur Spine J. 2006:15:1312-9.

3. Kuisma M, Karppinen J, Niinimäki J, et al. Modic changes in endplates of lumbar vertebral bodies: prevalence and association with low back and sciatic pain among middle-aged male workers. Spine (Phila Pa 1976). 2007; 32:1116-22

4. Saukkonen J, Määttä J, Oura P, et al. Association between Modic changes and low back pain in middle age: a northern Finland birth cohort study [published online ahead of print, 2020 Apr 23]. Spine (Phila Pa 1976). 2020 doi: https://doi.org/10.1097/BRS.0000000000003529.

5. Herlin C, Kjaer P, Espeland A, et al. Modic changes-their associations with low back pain and activity limitation: a systematic literature review and meta-analysis. PLoS One. 2018;13:e0200677.

6. de Roos A, Kressel H, Spritzer C, Dalinka M. MR imaging of marrow changes adjacent to end plate in degenerative lumbar disc disease. Am J Roentgenol. 1987;149:531-4.

7. Modic MT, Steinberg PM, Ross JS, Masaryk TJ, Carter JR. Degenerative disk disease: assessment of changes in vertebral body marrow with MR imaging. Radiology. 1988;166:193-9.

8. Modic MT, Masaryk TJ, Ross JS, Carter JR. Imaging of degenerative disk disease. Radiology. 1988;168:177-86.

9. Dudli S, Fields AJ, Samartzis D, Karppinen J, Lotz JC. Pathobiology of Modic changes. Eur Spine J. 2016;25:3723-34. 
10. Kuisma M, Karppinen J, Niinimäki J, et al. A three-year follow-up of lumbar spine endplate (Modic) changes. Spine (Phila Pa 1976). 2006;31:1714-8.

11. Jensen TS, Kjaer P, Korsholm L, et al. Predictors of new vertebral endplate signal (Modic) changes in the general population. Eur Spine J. 2010;19:12935.

12. Määttä JH, Karppinen Jl, Luk KD, Cheung KM, Samartzis D. Phenotype profiling of Modic changes of the lumbar spine and its association with other MRI phenotypes: a large-scale population-based study. Spine J. 2015; 15:1933-42.

13. Määttä JH, Rade M, Freidin MB, Airaksinen O, Karppinen J, Williams FMK. Strong association between vertebral endplate defect and Modic change in the general population. Sci Rep. 2018;8:16630.

14. Kuisma M, Karppinen J, Haapea M, et al. Are the determinants of vertebral endplate changes and severe disc degeneration in the lumbar spine the same? A magnetic resonance imaging study in middle-aged male workers BMC Musculoskelet Disord. 2008;9:51.

15. Leboeuf-Yde C, Kjaer P, Bendix T, Manniche C. Self-reported hard physical work combined with heavy smoking or overweight may result in so-called Modic changes. BMC Musculoskelet Disord. 2008;9:5.

16. Arana E, Kovacs FM, Royuela A, et al. Modic changes and associated features in southern European chronic low back pain patients. Spine J. 2011; 11:402-11.

17. Wu J, Huang J, Battié MC, Wang Y. Lifestyle and lifetime occupational exposures may not play a role in the pathogenesis of Modic changes on the lumbar spine MR images. Spine J. 2020;20:94-100.

18. Han C, Kuang MJ, Ma JX, Ma XL. Prevalence of Modic changes in the lumbar vertebrae and their associations with workload, smoking and weight in northern China. Sci Rep. 2017;7:46341 Published 2017 Apr 12.

19. Zhang YH, Zhao CQ, Jiang LS, Chen XD, Dai LY. Modic changes: a systematic review of the literature. Eur Spine J. 2008;17:1289-99.

20. Jensen RK, Leboeuf-Yde C. Is the presence of modic changes associated with the outcomes of different treatments? A systematic critical review. BMC Musculoskelet Disord. 2011;12:183.

21. Jensen TS, Karppinen J, Sorensen JS, Niinimäki J, Leboeuf-Yde C. Vertebral endplate signal changes (Modic change): a systematic literature review of prevalence and association with non-specific low back pain. Eur Spine J. 2008;17:1407-22.

22. Von Elm E, Altman D, Egger M, et al. The Strengthening the Reporting of Observational Studies in Epidemiology (STROBE) statement: guidelines for reporting observational studies. Prev Med. 2007:45:247-51.

23. University of Oulu. Northern Finland Cohorts. 2020. http://www.oulu.fi/nfbc/. Accessed 24 Feb 2020.

24. Rantakallio P. The longitudinal study of the northern Finland birth cohort of 1966. Paediatr Perinat Epidemiol. 1988;2:59-88.

25. Kinnunen $H$, Tanskanen $M$, Kyröläinen $H$, Westerterp KR. Wrist-worn accelerometers in assessment of energy expenditure during intensive training. Physiol Meas. 2012;33:1841-54.

26. Jauho AM, Pyky $R$, Ahola $R$, et al. Effect of wrist-worn activity monitor feedback on physical activity behavior: a randomized controlled trial in Finnish young men. Prev Med Rep. 2015;22:628-34.

27. Brugniaux JV, Niva A, Pulkkinen I, Laukkanen RM, Richalet JP, Pichon AP. Polar Activity Watch 200: a new device to accurately assess energy expenditure. Br J Sports Med. 2010:44:245-9.

28. Niemelä MS, Kangas M, Ahola RJ, et al. Dose-response relation of selfreported and accelerometer-measured physical activity to perceived health in middle age-the northern Finland birth cohort 1966 study. BMC Public Health. 2019:19:21.

29. Stirling A, Worthington T, Rafiq M, Lambert PA, Elliott TS. Association between sciatica and Propionibacterium acnes. Lancet. 2001:357:2024-5.

30. Ma XL, Ma JX, Wang T, Tian P, Han C. Possible role of autoimmune reaction in Modic type I changes. Med Hypotheses. 2011;76:692-4.

31. Karppinen J, Solovieva S, Luoma K, Raininko R, Leino-Arjas P, Riihimäki H. Modic changes and interleukin 1 gene locus polymorphisms in occupational cohort of middle-aged men. Eur Spine J. 2009:18:1963-70.

32. Wu H-L, Ding WY, Shen $Y$, et al. Prevalence of vertebral endplate modic changes in degenerative lumbar scoliosis and its associated factors analysis. Spine (Phila Pa 1976). 2012;37:1958-64.

33. Jensen RK, Kent $P$, Hancock M. Do MRI findings identify patients with chronic low back pain and Modic changes who respond best to rest or exercise: a subgroup analysis of a randomised controlled trial. Chiropr Man Therap. 2015;23:26.
34. Mok FP, Samartzis D, Karppinen J, Fong DY, Luk KD, Cheung KM. Modic changes of the lumbar spine: prevalence, risk factors, and association with disc degeneration and low back pain in a large-scale population-based cohort. Spine J. 2016;16:32-41.

35. Oura P, Karppinen J, Niinimäki J, Junno J. Search for lifetime determinants of midlife vertebral size: Emphasis on lifetime physical activity and early-life physical growth. Oulu: University of Oulu; 2017.

36. Slootmaker SM, Schuit AJ, Chinapaw MJ, Seidell JC, van Mechelen W. Disagreement in physical activity assessed by accelerometer and self-report in subgroups of age, gender, education and weight status. Int J Behav Nutr Phys Act. 2009;25:17.

37. Cain KL, Sallis JF, Conway TL, Van Dyck D, Calhoon L. Using accelerometers in youth physical activity studies: a review of methods. J Phys Act Health. 2013;10:437-50.

38. Schaefer SE, Van Loan M, German JB. A feasibility study of wearable activity monitors for pre-adolescent school-age children. Prev Chronic Dis. 2014;11: E85 Available from: https://www.cdc.gov/pcd/issues/2014/13_0262.htm. Cited 31 May 2018.

39. Gorzelitz J, Peppard PE, Malecki K, Gennuso K, Nieto FJ, Cadmus-Bertram L. Predictors of discordance in self-report versus device-measured physical activity measurement. Ann Epidemiol. 2018;28:427-31.

40. Kowalski K, Rhodes R, Naylor P, Tuokko H, Macdonald S. Direct and indirect measurement of physical activity in older adults: a systematic review of the literature. Int J Behav Nutr Phys Act. 2012;9:148.

41. Rosenberger ME, Haskell WL, Albinali F, Mota S, Nawyn J, Intille S. Estimating activity and sedentary behavior from an accelerometer on the hip or wrist. Med Sci Sports Exerc. 2013;45:964-75.

42. Skender S, Ose J, Chang-Claude J, et al. Accelerometry and physical activity questionnaires - a systematic review. BMC Public Health. 2016;16:515.

43. Troiano R, McClain J, Brychta R, et al. Evolution of accelerometer methods for physical activity research. Br J Sports Med. 2014;48:1019-23.

44. Saint-Maurice PF, Troiano RP, Berrigan D, Kraus WE, Matthews CE. Volume of light versus moderate-to-vigorous physical activity: similar benefits for allcause mortality? J Am Heart Assoc. 2018;7(7):e008815.

45. Jepsen DB, Thomsen K, Hansen S, Jørgensen NR, Masud T, Ryg J. Effect of whole-body vibration exercise in preventing falls and fractures: a systematic review and meta-analysis. BMJ Open. 2017;7:e018342.

46. Da Silva SG, Evenson KR, Ekelund U, et al. How many days are needed to estimate wrist-worn accelerometry-assessed physical activity during the second trimester in pregnancy? PLoS One. 2019;14:e0211442.

47. Dillon CB, Fitzgerald AP, Kearney PM, et al. Number of days required to estimate habitual activity using wrist-worn GENEActiv accelerometer: a cross-sectional study. PLoS One. 2016;11:e0109913.

48. Ricardo LIC, Wendt A, Galliano LM, et al. Number of days required to estimate physical activity constructs objectively measured in different age groups: findings from three Brazilian (Pelotas) population-based birth cohorts. PLoS One. 2020;15:e0216017.

49. Trost $S$, Pate $R$, Freedson $P$, et al. Using objective physical activity measures with youth: how many days of monitoring are needed? Med Sci Sports Exerc. 2000;32:426-31.

50. Telama R. Tracking of physical activity from childhood to adulthood: a review. Obes Facts. 2009;2:187-95.

\section{Publisher's Note}

Springer Nature remains neutral with regard to jurisdictional claims in published maps and institutional affiliations.

Ready to submit your research? Choose BMC and benefit from:

- fast, convenient online submission

- thorough peer review by experienced researchers in your field

- rapid publication on acceptance

- support for research data, including large and complex data types

- gold Open Access which fosters wider collaboration and increased citations

- maximum visibility for your research: over $100 \mathrm{M}$ website views per year

At $\mathrm{BMC}$, research is always in progress.

Learn more biomedcentral.com/submission 